\title{
PELATIHAN JIWA KEPEMIMPINAN KEPADA KOMUNITAS PENCINTA ALAM KELURAHAN PONDOK PUCUNG
}

\author{
Nopi Oktavianti ${ }^{1}$, Nariah $^{2}$, Imbron $^{3}$, Abdul Rahman Safiih ${ }^{4}$, \\ Hafis Laksmana Nuraldy ${ }^{5}$ \\ Universitas Pamulang \\ Email: dosen02481@unpam.ac.id
}

\begin{abstract}
This service activity aims to provide leadership and organizational management provisions to all members of the organization in the form of leadership mental counseling, leadership coaching, cohesiveness, responsibility in carrying out organizational activities, training and developing leadership skills for all members of the ARIMBIN Nature Lovers Community in Pondok Pucung Village. In the future, anyone who later becomes the leader of the organization will have the appropriate leadership character to be able to play an important role in the organization properly. A leader must have a character that is firm, respected, dignified, able to invite other members to work in the team, be able to motivate members, be able to make decisions with careful consideration, and so on. The results of this activity show that before the implementation of this PKM all members still lacked mastery of the material about leadership, but after the implementation of the activities the PKM activity participants were able to understand the very broad aspects of leadership, this can all be seen from the results of the question and answer session given. to the participants during this PKM activity. The method used is to provide training through providing leadership materials to all members of the ARIMBIN Nature Lovers Community then discussing together the problems that exist within the organization so that they can provide the right solution.
\end{abstract}

\section{Keywords: PKM, Leadership, Organization}

\begin{abstract}
ABSTRAK
Kegiatan Pengabdian ini bertujuan untuk memberikan bekal kepemimpinan dan manajemen organisasi kepada seluruh anggota organisasi dalam bentuk penyuluhan mental kepemimpinan, pembinaan kepemimpinan, kekompakan, tanggung jawab dalam menjalankan kegiatan organisasi melatih dan mengembangkan jiwa kepemimpinan kepada seluruh anggota Komunitas Pecinta Alam ARIMBIN yang berada di Kelurahan Pondok Pucung, kelak siapa saja yang nantinya menjadi pemimpin organisasi tersebut sudah mempunyai bekal karakter pemimpin yang layak agar mampu memegang peran penting didalam organisasi dengan baik. Seorang pemimpin harus mempunyai karakter yang tegas, disegani, wibawa, bisa mengajak anggota lain untuk bekerja dalam tim, bisa memotivasi anggota, bisa mengambil keputusan dengan pertimbangan yang matang dan lain sebagainya. Hasil kegiatan ini menunjukan bahwa sebelum pelaksanaan PKM ini seluruh anggota masih kurang menguasai materi tentang
\end{abstract}


kepemimpinan, namun setelah pelaksanaan kegiatan dilakukan peserta kegiatan PKM ini sudah dapat memahami aspek-aspek kepemimpinan yang sebenarnya sangat luas, ini semua dapat terlihat dari hasil sesi tanya jawab yang diberikan kepada peserta saat kegiatan PKM ini berlangsung. Metode yang digunakan adalah memberikan pelatihan melalui pembekalan materi kepemimpinan kepada seluruh anggota Komunitas Pecinta Alam ARIMBIN kemudian berdiskusi bersama terkait permasalahan yang ada didalam organisasi tersebut sehingga dapat memberikan solusi yang tepat.

\section{Kata Kunci: PKM, Leadership, Organisasi.}

\section{A. PENDAHULUAN}

Menurut Tim Elmore, seorang penulis didalam bukunya tentang kepemimpinan, terdapat dua jenis seorang pemimpin,yaitu "habitual leader" dan "situational leader". Habitual leader adalah orang yang secara sudah terbiasa untuk memimpin di keadaan apapun. Memang sangat beruntung memiliki jiwa kepemimpinan yang satu ini. Tapi bukan berarti "situational leader" itu buruk. Situational leader dibentuk dari situasi-situasi yang bisa mereka manfaatkan untuk menunjukkan kekuatan mereka.Seorang pemimpin yang memiliki jiwa leadership adalah pemimpin yang dengan terampil mampu melakukan kombinasi dan improvisasi dalam menggunakan genesis kekuasaan yang berbeda untuk mempengaruhi perilaku bawahan dalam berbagai situasi. Inilah yang disebut penulis dalam kalimat sebelumnya sebagai kepemimpinan yang efektif (effective leadership), dimana implementasinya adalah dengan "memanfaatkan genesis kekuasaan, dan menerapkannya pada tempat yang tepat"

Kepemimpinan dalam organisasi adalah sebuah proses dimana seorang pemimpin memengaruhi dan memberikan contoh kepada pengikutnya dalam upaya mencapai tujuan organisasi. Pemimpin yang baik bukan dilihat dari seberapa banyak orang yang menjadi pengikutnya, bukan juga dilihat dari seberapa lama ia memimpin. Pemimpin yang baik dilihat dari seberapa banyak ia mampu menciptakan sosok pemimpin yang baru. Kepemimpinan menjadi salah satu faktor penting bagi keberhasilan sebuah organisasi. Untuk itu, ada beberapa sikap kepemimpinan dalam organisasi yang perlu diterapkan oleh seorang pemimpin.

1. Menjalin kedekatan dengan anak buah

Kepemimpinan dalam organisasi akan menjadi lebih efektif jika seorang pemimpin telah mendapat respek dari anak buah. Hal ini bisa dibangun dengan menjalin kedekatan dengan mereka, sehingga mereka akan percaya dan mau mengikuti arahan Pemimpin.

2. Memberikan semangat dan motivasi

Kepemimpinan dalam organisasi bukan melulu soal pangkat dan jabatan, tetapi kepemimpinan adalah bagaimana seorang pemimpin dapat memberikan semangat dan motivasi, bahkan untuk setiap hal kecil dari pekerjaan yang anak buah pimpinan lakukan.

3. Memberikan Kepercayaan dan tanggung Jawab

Kepemimpinan dalam organisasi adalah tentang kepercayaan. Berikan anak buah Pemimpin kepercayaan dan tanggung jawab yang lebih dalam melakukan tugas mereka. Jika ada hal yang tidak sejalan, jangan langsung menghakimi. Berikanlah feedback agar ke depannya mereka tidak takut salah dalam mengambil sebuah keputusan. Agar seseorang dapat menjadi pemimpin yang baik, tentunya akan dibutuhkan

Identifikasi masalah yang ditemukan di lapangan adalah masih kurangnya pemahaman dan pengetahuan para remaja pecinta alam kelurahan pondok pucung khususnya Pengurus 
dalam hal mengatur diri dan membuat perencanaan kerja serta mengarahkan diri dalam membuat keputusan. Hal itu dikarenakan para anggota mayoritas masih belum memiliki pemahaman dan sikap dalam berorganisasi yang baik. Sehingga diperlukan Pelatihan Dasar Kepemimpinan untuk membentuk sikap dan mental mereka dalam berorganisasi.

Pecinta Alam adalah seseorang yang mencintai Alam dan semesta beserta isinya. Jadi pecinta Alam artinya sangat luas sekali, mencintai Hutan, Gunung, Laut, Bumi, Bulan, Matahari dan sebagainya. Termasuk juga mencintai Manusia, mencintai diri sendiri, bahkan mencitai Tuhan Yang Maha Esa, yang telah menciptakan alam semesta beserta isinya, jadi pada hakekatnya pecinta alam itu sangat luas artinya. (Marlia Husna, 2007:1)

Dalam pendakian gunung keselamatan diperhatikan juga, seperti tertera diatas, tidak selalu perjalanan berjalan dengan lancar. seperti yang diinginkan, atau tidak sesuai dengan apa yang direncanakan, karena banyak faktor-faktor yang terjadi dilapangan, seperti cuaca yang tidak menentu selalu berubah ubah. Oleh sebab itu bagaimana semestinya prilaku pendaki gunung dalam mengatur keselamatan dan manajemen keselamatan dalam pendakian gunung.

Pada saat ini banyak terjadi kecelakaan di gunung seperti tersesat, kehilangan jalur, fisik yang kurang memadai dan mental yang tidak siap menerima keadaan alam (cuaca buruk dan berkabut) yang mengakibatkan hilangnya jalur pendakian, namun bagi penggiat alam bebas hal-hal tersebut bisa diatasi, karena mereka mempunyai bekal yang cukup untuk menghadapi hal yang demikian, seperti pelatihan dan pengalaman yang banyak mereka kantongi, rata-rata dari korban kecelakaan digunung disebabkan oleh lemahnya fisik, tidak mengatur pola makan dan gizi, sehingga membahayakan kesehatannya dalam pendakian gunung, atau tidak memperhatikan manajemen perjalanan, seperti membawa perlengkapan kurang memadai yang mendatangkan bahaya bagi para pendaki, sehingga menimbukan kecelakaan. Oleh karena itu membutuhkan seorang leader atau jiwa pemimpin agar setiap pendakian dapat berjalan sesuai harapan.

Leader diberi tugas untuk memimpin pendakian dan membuka jalur dalam kelompok pendaki. Sebagai pemimpin dalam kelompok pendakian, seorang Leader harus memiliki fisik yang kuat, memiliki sifat antusiasme, mampu memotivasi, pintar, mudah beradaptasi, memiliki pengetahuan luas, mau menerima masukan, serta tidak mudah menyerah. Hal ini bisa dipahami karena tugas seorang Leader pendakian cukup berat yaitu agar perjalanan pendakian terorganisir dan berjalan sesuai rencana. Untuk itu seorang Leader juga harus bisa berkoordinasi dengan baik dengan Navigator.

Materi yang diberikan oleh pemateri berkaitan dengan kepemimpinan berupa penyuluhan mengenai karakter pemimpin yang benar. Dilanjutkan dengan sesi komunikasi yang meliputi penyuluhan mengenai cara-cara berkomunikasi yang benar sebagai layaknya seorang pemimpin. Selain itu, ada juga sesi problem solving yaitu mengenai cara-cara seorang pemimpin memecahkan masalah secara efektif dan benar. Ada pula sebuah dinamika kelompok yang disajikan dalam permainan. Dan kegiatan ditutup dengan pembagian sertifikat oleh panitia kepada peserta latihan dasar kepemimpinan.

Materi yang dibutuhkan akan disampaikan oleh para pemateri berkaitan dengan kepemimpinan berupa penyuluhan mengenai karakter pemimpin yang benar, ketrampilan menyusun rencana kerja dan pengambilan keputusan dilanjutkan dengan sesi komunikasi yang meliputi penyuluhan mengenai cara-cara berkomunikasi yang benar sebagai layaknya seorang pemimpin. Selain itu, ada juga sesi problem solving yaitu mengenai cara-cara seorang pemimpin memecahkan masalah secara efektif dan benar. Ada pula sebuah dinamika kelompok yang disajikan dalam permainan. Dan kegiatan ditutup dengan pembagian sertifikat oleh panitia kepada peserta Latihan Dasar Kepemimpinanya. Pendakian Gunung adalah salah satu olahraga favorit bagi pecinta alam atau penggiat alam bebas. 
Sebuah olahraga yang berisiko tinggi yang bisa menyebabkan kematian, yang membutuhkan stamina fisik, mental, kesehatan dan strategi yang matang. Saat ini banyak terjadi kecelakaan digunung seperti tersesat, kehilangan jalur, fisik yang kurang memadai dan mental yang tidak siap menerima keadaan alam (cuaca buruk dan berkabut). Namun bagi penggiat alam bebas hal-hal tersebut bisa diatasi karena mereka mempunyai bekal yang cukup untuk menghadapi hal yang demikian seperti pelatihan dan pengalaman yang banyak dikantongi.

\section{B. METODE PELAKSANAAN}

Metode kegiatan ini berupa pelatihan jiwa kepimipinan yang berbentuk diskusi dan ceramah dengan hasil pembuatan akun media sosial.

Berikut ini adalah tahapan pelatihan yang dilakukan :

1. Survei Tempat Pelaksanaan Kegiatan

Kegiatan ini dimaksudkan untuk menggali informasi tentang kondisi geografis dan kondisi masyarakat didaerah tempat kegiatan. Informasi tersebut berupa lokasi, permasalahan yang dihadapi dalam pada lokasi tersebut

2. Persiapan Sarana dan Prasarana.

Kegiatan ini dimaksudkan untuk merencanakan kebutuhan baik sarana dan prasarana yang akan digunakan dalam pelaksanaan kegiatan dengan tetap memperhatikan kebutuhan masyarakat secara umum dan khusus demi tercapainya target pengabdian kepada masyarakat. Sarana dan prasarana yang dimaksud berupa projektor, spanduk daln lain-lain.

3. Pelaksanaan Kegiatan.

Setelah melakukan survey dan persiapan sarana dan prasarana maka pelaksanaan kegiatan dilaksanakan oleh pengusul besrta anggota dan beberapa mahasiswa. Kegiatan yang dilakukan adalah berupa pelatihan atau penyuluhan dalam bentuk pertemuan secara langsung dengan para anggota komunitas Arimbin, pondok pucung, tangerang selatan

4. Monitoring dan Evaluasi.

Kegiatan ini dimaksudkan untuk meninjau perkembangan aktualisasi masyarakat terhadap kegiatan yang telah dilakukan sebelumnya dengan harapan dapat dilaksanakan sesuai dengan teori yang telah di peroleh melalui kegiatan yang telah dilaksanakan. Evaluasi juga bertujuan untuk memahami pola pemahaman masyrakat terhadap informasi atau pengetahuan baru yang diperoleh dari pelaksana kegiatan. Hasil ini diharapkan mampu menjadi dasar penghetahuan meningkatkan softskill dengan tema Pelatihan jiwa kepemimpinan pada komunitas pecinta alam kelurahan pondok pucung.

Dalam pelatihan ini, nara sumber berfokus kepada Sasaran kegiatan Pengabdian kepada masyarakat (PKM) ini adalah dengan merangkul anggota komunitas pecinta alam khususnya Pengurus untuk mengikuti kegiatan meningkatkan softskill dengan tema Pelatihan jiwa kepemimpinan pada komunitas pecinta alam kelurahan pondok pucung.

\section{HASIL DAN PEMBAHASAN}

Peserta yang hadir sebanyak 25 warga masyarakat yang terdiri dari perwakilan ketua Arimbin dan para anggota kmunitas arimbin, para dosen dan Mahasiswa Universitas Pamulang. Kegiatan dilaksanakan melalui diskusi tanya jawab, dengan cara para narasumber memberikan penyuluhan dan diikuti oleh para peserta yang kumpul di aula masjid diarea pondok pucung Tangerang selatan terlihat sangat antusias menyimak paparan materin dengan menggunakan sebuah laptop yang disambungan ke LCD. Kegiatan berjalan baik dan lancer, banyaknya peserta yang antusias untuk bertanya,berdiskusi tentang jiwa kepemimpinan yang menjadikan para nara sumber lebih bersemangat lagi untuk memberikan penyuluhan. 
Kreatifitas adalah proses pemikiran yang membantu mencetuskan berbagai gagasan baru yang merupakan salah satu sifat manusia yang dibentuk dari proses pengalaman sehingga orang tersebut bisa terus memperbaiki dan mengembangkan dirinya (Anderos:1961). Menurut Baron (1969) kreatif adalah kemampuan untuk menciptakan sesuatu yang baru. Dari dua pendapat tersebut dapat disimpulkan bahwa kreatif adalah kemampuan yang ada dalam diri seseorang untuk membuat sesuatu atau memunculkan ide yang berbeda dari yang ada sebelumnya. Berdasarkan IBM CEO Study, sebanyak 1500 CEO dari berbagai negara menganggap kreatif merupakan kemampuan leadership yang paling dibutuhkan agar suatu perusahaan dapat sukses di masa depan. Hal itu dikarenakan dunia selalu mengalami perubahan yang sangat cepat dan tidak menentu sehingga jika seorang pemimpin tidak bisa berpikir kreatif, maka produk atau jasa perusahaan tersebut akan tidak berkembang dan para pelanggan akan meninggalkan produk atau jasa itu dan beralih ke perusahaan lain.

Menurut Gerard J. Puccio dengan adanya perubahan, sebuah organisasi dapat naik dan turun lebih cepat dari sebelumnya, dibuktikan dengan perusahaan Blockbuster, Nokia, dan Motorola. Kreativitas sangat dibutuhkan untuk menghadapi peningkatan dunia bisnis yang semakin kompleks dengan munculnya berbagai kompetitor yang semakin memacu seorang pemimpin agar berpikir kreatif dalam mengatasi persaingan dengan para competitor. Seorang Pemimpimpin yang kreatif juga memberikan inspirasi kepada karyawannya untuk selalu memikirkan ide-ide baru sehingga dengan banyaknya ide baru tujuan suatu perusahaan lebih mudah tercapai secara efektif dan efisien daripada menggunakan strategi yang sama terus-menerus. Pemimpin harus menjadi pribadi yang kreatif tangguh, mandiri, memiliki jatidiri dan mampu anggotanya dalam suatu organisasi. Keberhasilan suatu organisasi ditentukan dari pemimpin yang mampu mengajak organisasi mencapai tujuan yang jelas. harapan segala wawasan dan pengetahuan dalam pelatihan jiwa kepemimpinan ini mampu diterapkan mahasiswa dan kedepannya mahasiswa ini mampu jadi pemimpin bangsa. Hal ini bisa dipahami karena tugas seorang Leader pendakian cukup berat yaitu agar perjalanan pendakian terorganisir dan berjalan sesuai rencana. Untuk itu seorang Leader juga harus bisa berkoordinasi dengan baik dengan Navigator

Untuk itu dosen dan mahasiswa perlu mengadakan pelatihan jiwa kepemimpinan pada sebuah komunitas tersebut guna menambah ilmu dan membangun semangat jiwa kepemimpinan dalam diri mereka. Seorang Leader harus bisa cepat mengambil keputusan untuk menghentikan pendakian, bila memang terjadi hal yang membahayakan saat pendakian. Pulang dengan selamat ke rumah masing-masing tentu lebih penting dibandingkan ambisi mencapai puncak gunung namun membahayakan jiwa.

\section{KESIMPULAN DAN SARAN}

\section{Kesimpulan}

Pelaksanaan kegiatan pengabdian masyarakat oleh lembaga penelitian dan pengembangan masyarakat (LPPM) Universitas Pamulang yang dilakukan oleh dosen-dosen program studi Pendidikan Ekonomi dan Manajemen telah berjalan dengan lancar dan mendapat sambutan hangat dari tempat pelaksanaan kegiatan ini yaitu para anggota komunitas pencinta alam kelurahan pondok pucung. Dengan ada kegiatan ini menjadikan para anggota Pengurus di lingkungan komunitas pencinta alam kelurahan pondok pucung dapat memahami pentingnya pelatihan dasar kepemimpinan milenial. 


\section{Saran}

Selama kegiatan berlangsung peserta penyuluhan memberikan tanggapan yang sangat baik, hal ini dapat dilihat dari dukungan dan atusiasme mereka dalam setiap kegiatan yang diadakan. Selain itu harapan kami dengan pengabdian ini dapat membuka wawasan dari para anggota Pengurus, sehingga tidak hanya memberikan tambahan pengetahuan tetapi juga dapat diterapkan khususnya dalam menerapkan kemampuan berorganisasi. Selain itu diharapkan juga dapat membantu dan meningkatkan kepemimpinan mereka dengan pendekatan terkini atau milenial.

\section{Ucapan Terima Kasih}

Rasa syukur dan suka cita kamu haturkan kepada segenap pihak yang telah mensukseskan kegiatan PKM dengan judul "Pelatihan Jiwa Kepemimpinan Kepada Komunitas, Pecinta Alam Kelurahan Pondok Pucung" kepada:

1. Rektor Dr. H. Dayat Hidayat, M.M, Rektor Universitas Pamulang, Tangerang Selatan Banten.

2. Dr. Ali Maddinsyah, S.E., M.M., selaku Ketua LPPM Universitas Pamulang, Tangerang Selatan - Banten.

3. Dr. Kasmad, S.E., M.,M., selaku Ketua Program Studi Manajemen S1 Universitas Pamulang, Tangerang Selatan - Banten.

4. Dr. Udin Ahidin, S.E., M.M., C.M.A, Selaku Wakil Program Studi Manajemen S1 Universitas Pamulang, Tangerang Selatan - Banten.

5. Drs. Waluyo Jati, M.M., Selaku Sekretaris Program Studi Manajemen S1 Universitas Pamulang Tangerang Selatan - Banten.

6. Pimpinan Ketua Yayasan Al- Hikam Abdul Majid, S.T., M.Si yang telah memberikan izin tempat serta kemudahan dalam pelaksanaan pengabdian.

7. Bapak/Ibu Dosen dan Mahasiswa Universitas Pamulang yang telah membantu kelancaran pelaksanaan kegiatan pengabdian ini.

8. Orang Tua dan keluarga kami tercinta yang selalu memberikan dukungan dan motivasi dan selalu mengiringi doa dan restu.

\section{DAFTAR PUSTAKA}

Aidinil Zetra. Gaya Kepemimpinan (Bahan Bacaan Kuliah Kepemimpinan Politik). Padang : Magister Ilmu Politik Universitas Andalas.

Ali, E. M. (2012). Kepemimpinan transformasional dalam birokrasi pemerintahan. Multicerdas Pub..

Ariyanto, A., Sudarsono, A., Ivantan, I., Akbar, M. F., \& Munarsih, M. (2020). Pengembangan Potensi Destinasi Wisata Curug Angkrek melalui Media Sosial di Kp. Cimuncang, Desa Karangnunggal, Kabupaten Tasikmalaya Jawa Barat. BAKTIMAS: Jurnal Pengabdian pada Masyarakat, 2(2), 95-99.

Asep Suryana. (2013). Value Based Leadership. Bandung : Nurani Press.

Bass, B. M \& Riggio, R.E. (2006). Transformational leadership (2nded.).

Eko Prasojo, dkk. (2013). Pemimpin dan Reformasi Birokrasi : Catatan Inspiratif Dan Alat Ukur Kepemimpinan Dalam Implementasi Reformasi Birokrasi. Kementerian Pendayagunaan Aparatur Negara dan Reformasi Birokrasi. 
Fayol dalam Tim Dosen. (2016). Modul Perkuliahan Menajemen Pusat Data: Menajemen Kepemimpinan dan Tim. Universitas Mercu Buana : Jakarta.

Fread, Friedler dalam Mukeri. Kepemimpinan Dan Kekuasaan Suatu Tinjauan Perilaku Organisasi.Dosen Jurusan Manajemen Fakultas Ekonomi Universitas Pandanaran.

Gary Yulk. (2010). Kepemimpinan Dalam Organisasi; terj. Budi Supriyanto.PT. Indeks:Jakarta

Mahwah, NJ., Erlbaum. Deddy Mulyana. (2001). Metode Penelitian Kualitatif, Paradigma Baru Ilmu Komunikasi \& Ilmu Sosial lainnya. Bandung: Remaja Rosdakarya.

Munarsih, M., Akbar, M. F., Ariyanto, A., Ivantan, I., \& Sudarsono, A. (2020). Pelatihan Digital Marketing Dalam Meningkatkan Kompetensi Siswa Untuk Berwirausaha Pada Smk Muhammadiyah Parung-Bogor. Jurnal Pengabdian Dharma Laksana, 3(1), 22-28.

Oktavianti, N. (2020). Pengaruh Motivasi dan Kepuasan Kerja terhadap Kinerja Kerja Karyawan PT. DEW Indonesia. JENIUS (Jurnal Ilmiah Manajemen Sumber Daya Manusia), 3(2), 148-155.

Umar, T. (2011). Pengaruh Outbond Training terhadap Peningkatan Rasa Percaya Diri Kepemimpinan dan Kerjasama Tim. Jurnal Ilmiah SPIRIT, 11(3).

Pramudyo, A. (2013). Implementasi manajemen kepemimpinan dalam pencapaian tujuan organisasi. Jurnal Bisnis, Manajemen, dan Akuntansi, 1(2).

Prasada, D., Oktavianti, N., \& Kristianti, L. S. (2020). PENGARUH PEMBERIAN REWARD DAN MOTIVASI TERHADAP PRODUKTIVITAS KARYAWAN PADA PT. SINAR KENCANA JAYA DI SURABAYA. Jurnal Ekonomi Efektif, 3(1). 